\title{
Computerized Digital Image Processing on Radiographs of Canine Filariosis
}

\author{
Katsuyuki MIYATAKE, Yoshiharu OKAMOTO and Saburo MINAMI* \\ United Graduate School of Veterinary Sciences, Yamaguchi University, Yamaguchi 753-0841, Japan
}

(Received 20 August 1998/Accepted November 2 1998)

\begin{abstract}
For objective evaluation in the lung arterial lesions, density histogram revealed by survey thoracic radiographies of fifteen canine filariosis and five normal canine were digitally analyzed, and preparation of pulmonary artery angiogram with inflated-fixed lung, the changes in the histogram and the pulmonary arterial lesion by a soft x-ray examination were compared. In the lung areas affected by filariosis, the density histogram increased the white level and decreased the black level in each part compared to a normal lung. In comparison with the normal parameters, those of the filariosis it were significantly increased in minimum grey level values (Min), maximum grey level values (Max), and the maximum frequency grey level values (Mode) and, it was significantly decreased in maximum frequency values $(\mathrm{MaF})$. The pulmonary arterial lesion of the filariosis showed obvious morphological changes such as in distinction, pruning, angiectasis, and meandering. In the grade of pulmonary arterial lesion, the parameter Min, Max, Mode and MaF were changed significantly. From these results, it was clear that the methods for the lung arterial lesions analysis of x-ray images were confirmed to be highly beneficial in the lung arterial lesions for objective diagnosis.-KEY wORDs: canine, digital image processing, filariosis, grey level, inflated fixed lung.
\end{abstract}

J. Vet. Med. Sci. 61(3): 245-250, 1999

In a small animal clinic, various congenital or acquired thoracic diseases are frequently encountered. Therefore, a radiographic thoracic examination is one of the most common diagnostic techniques. Canine filariosis is also a common pulmonary disease, and induces severe morphological changes in the heart and pulmonary system [5].

Many reports have dealt with cardiac evaluation $[3,7$, 13], but few have addressed pulmonary concerns [3]. It is usually difficult to numerize a pulmonary lesion, so its evaluation has been performed based on macroscopic findings of x-ray films, such as air-bronchogram, or embolism, pulmonary arterial dilation $[1,6,7]$.

We have previously reported on the role of computerized digital image processing of survey radiographs of a normal canine lung [10]. The density histogram of a normal canine thoracic radiograph showed stable standard values in its parameters, such as minimum grey level value, maximum grey level value, mean grey level value, and maximum frequency grey level value. Therefore, an evaluation of the pulmonary field was objectified by a computerized digital processing method [10].

In the present paper, we attempt to clarify the role of image processing of a diseased lung, especially in a case of filariosis with various degrees of pulmonary dysfunction which were also diagnosed by soft x-ray examination and preparation of inflated and fixed lung specimens [2].

\section{MATERIALS AND METHODS}

Animals: Twenty mixed-breed dogs were used for this

* Correspondence to: Dr. Minami, S., Department of Veterinary Surgery, Faculty of Agriculture, Tottori University, 4-101 Koyama-Minami, Tottori 680-8553, Japan. experiment. The thoracic $\mathrm{x}$-ray was performed by $\mathrm{x}$-ray devices (KXO-80F with beam limiting device model TF-6 TL-6, Toshiba, Japan), auto x-ray condition program (Anatomical Program, Toshiba, Japan), the films (Medical X-ray Film SR-G, Conika, Japan) and screen (Intensify screen KM-250, Conika, Japan) taken were developed and fixed by an auto-developing system (model Mini Auto MA14, Tanaka x-ray, Japan) before euthanasia. Dirofilaria immitis infection was confirmed by detection of microfilaria in the blood and radiographic findings of the right ventricle and the main truncus of the pulmonary artery, and was confirmed in 15 dogs. Another 5 dogs showed healthy lungs in radiographic examination and no parasites in the right ventricle or the pulmonary arteries at autopsy. The experimental subjects were divided into two groups: one normal (5 dogs) and the other filariosis (15 dogs). The normal dogs were 1 to 3 years old and weighed 5.5 to 15.0 $\mathrm{kg}$. The dogs with filariosis were 2 to 10 years old and weighed 6.5 to $19.0 \mathrm{~kg}$.

Grey level analysis of $x$-ray films: Five thoracic $\mathrm{x}$-ray films of the normal and fifteen thoracic $\mathrm{x}$-ray films of the filariosis dogs were used for image processing. X-ray exposure was performed in all dogs in a ventrodorsal position. An image analyzer (MV4000, Nippon Data General, Japan), a multi-color data system (4200F, NAC, Japan), TV camera (4200F, NAC, Japan), and an analysis software (ID300, NAC, Japan) were used for the digitalization of $\mathrm{x}$-ray images. Methods were based on those described in our previous report [10]. In brief, x-ray image was input into MV4000 via 4200F, and redisplayed on the screen of 4200F using the ID300's image file support programs, Define image file status (DIFS) and Define image status program (DISP). Image analysis on the lung field was performed by the MV4000 image processor. The pulmonary field was divided into right and left fields by the spine, and into cranial, middle and caudal parts at the level 

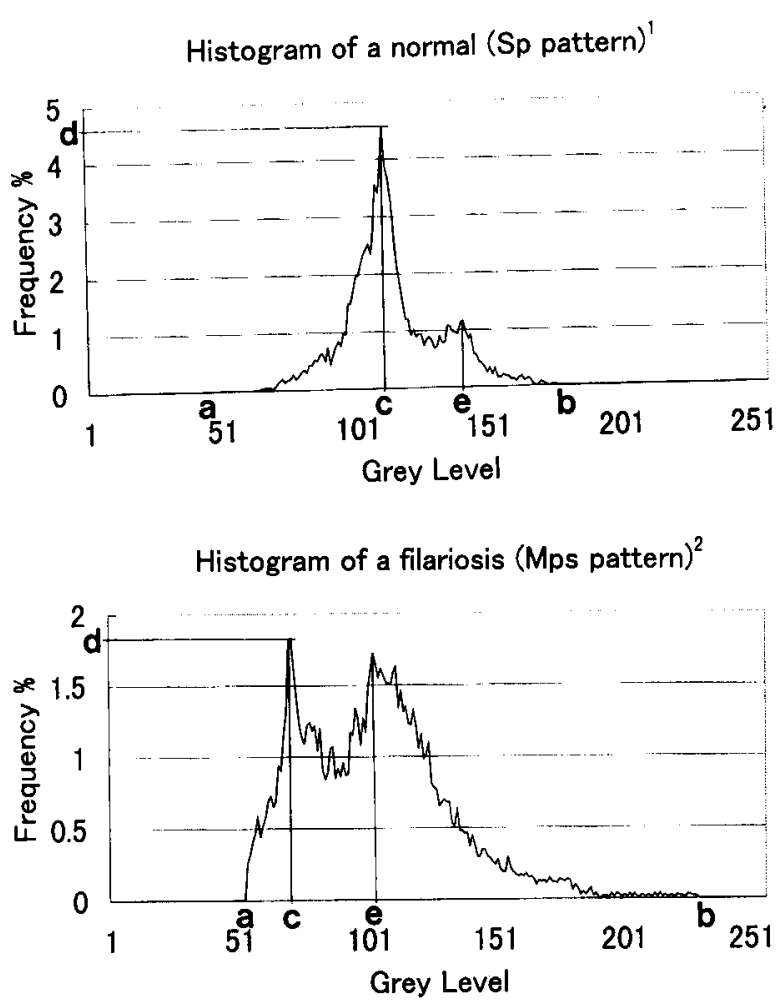

Fig. 1. Grey level histogram of canine survey chest $\mathrm{x}$-ray. 1: caudal part in the normal, 2: caudal part in the filariosis. a: minimum grey level value (Min) b: maximum grey level value (Max) c: maximum frequency grey level value (Mode) $\mathrm{d}$ : maximum frequency in Mode $(\mathrm{MaF})$ e: frequency value in the second peak.

of the 4th intercostal space and at the 8th intercostal space, respectively. Density histograms and parameters in $5 \%$ of the lung field area were obtained by ID300's analysis software program HGRAM. The parameters were minimum grey level value (Min), maximum grey level value (Max), mean grey level value (Mean), median grey level value (Med), maximum frequency grey level value (Mode), and maximum frequency value (MaF) (Fig. 1).

Classification of grey level histogram patterns: Each histogram was traced to the peak out line as shown in Fig. 1 , and each peak frequency was examined. The peaks were assumed "first", "second", and "others" respectively to their frequencies. The ratio (\%) of the first (c) to the second (e) was calculated (Fig. 1-2).

Preparation of inflated and fixed lung specimens: Lungs were collected from 20 dogs after euthanasia. The modified method preparing of inflated and fixed lung specimens was based on Bedros and Edwin [2]. General anesthesia was performed by the administration $25-30 \mathrm{mg} / \mathrm{kg}$ of pentobarbital sodium (Nembutal injection, Dainipponseiyaku, Japan) intravenously, after injection 100 IU/kg of heparin (Nobo-heparin, Noboindustry, Denmark) for anticoagulant treatment. The carotid artery was exposed for the treatment of exsanguination. After euthanasia, the lung along with the heart and part of the trachea were recovered. The right ventricle was incised, and then a catheter (extension tube, JMS, Japan) was placed in the pulmonary artery. Barium solution (BaSO4 $120 \mathrm{~g} / 100 \mathrm{ml}$, Baricate-R, Otsuka, Japan) was infused from the catheter. The injection pressure was measured by use of a manometer with a 3-way connector in the infusion line, and the barium injection pressure was maintained at $60 \mathrm{mmHg}$ [15]. After clamping the catheter, an intratracheal tube was inserted to the trachea and the lung was inflated with oxygen. The fixative which comprising about $10 \%$ of pulmonary weight was infused to lung through the trachea. The fixative consisted of polyethylene glycol 400 (Wako Pure Chem. Ind., Japan), 95\% ethyl alcohol (Wako Pure Chem. Ind., Japan), 37\% formaldehyde (Wako Pure Chem. Ind., Japan), and distilled water, in a rate of 25:10:10:55, respectively. The same fixative was also sprayed intermittently on the lung surfaces during air-drying. Oxygen pressure was maintained at 25 to $30 \mathrm{mmHg}$, monitored by a manometer, in order to prevent an artificial bulbous separation of the visceral pleura from the lung parenchyma by high oxygen pressure $(>30 \mathrm{mmHg}$ ) [2]. After $24 \mathrm{hr}$ of this treatment, fixation of the lung was obtained.

Soft $x$-ray examination of the inflated and fixed lung specimens: After inflation and fixation of the lung, each lobe was cut off. Thickest part of each lobe was measured to the set-up time of soft raies exposure (CMBW, Softex, Japan), soft x-ray film (LX, Fuji photo film, Japan). Exposure distance between the $\mathrm{x}$-ray tube and film was fixed at $40 \mathrm{~cm}$. Thirty and 90 lobes of the normal and filariosis lungs, respectively, were examined by the soft x-ray.

Lung vascular lesions were classified into 5 grades, as described as follows: no abnormal findings were observed in the grade 1 arterial systems (Fig. 2a); meandering of the peripheral vascular system (arrow), but no abnormal findings in main vascular trunks (Fig. 2b) were found in grade 2; meandering of the peripheral vascular system and angiectasis or pruning of the peripheral (arrow) vascular system were found in grade 3 (Fig. 2c); meandering with angiectasis (arrow), pruning of the peripheral vascular system and angiectasis in the main vascular trunks were observed in grade 4 (Fig. 2d); and meandering with angiectasis, pruning of the peripheral vascular system, angiectasis in the main vascular trunks and ill-definition of the peripheral vascular systems with a peripheral vascular increase (arrow) were observed in grade 5 (Fig. 2e).

Statistical analysis: The statistical analysis was performed by student's $t$ test at a $5 \%$ level.

\section{RESULTS}

The each parameter in the grey level histogram is shown in Table 1. In the normal group, each parameter value was highest in the cranial and lowest in the caudal areas, however, there were no significant differences in each parameter value among lung lobes. In comparison with the normal, the value of all lobes in the filariosis were significantly increased in minimum-, maximum-grey level 

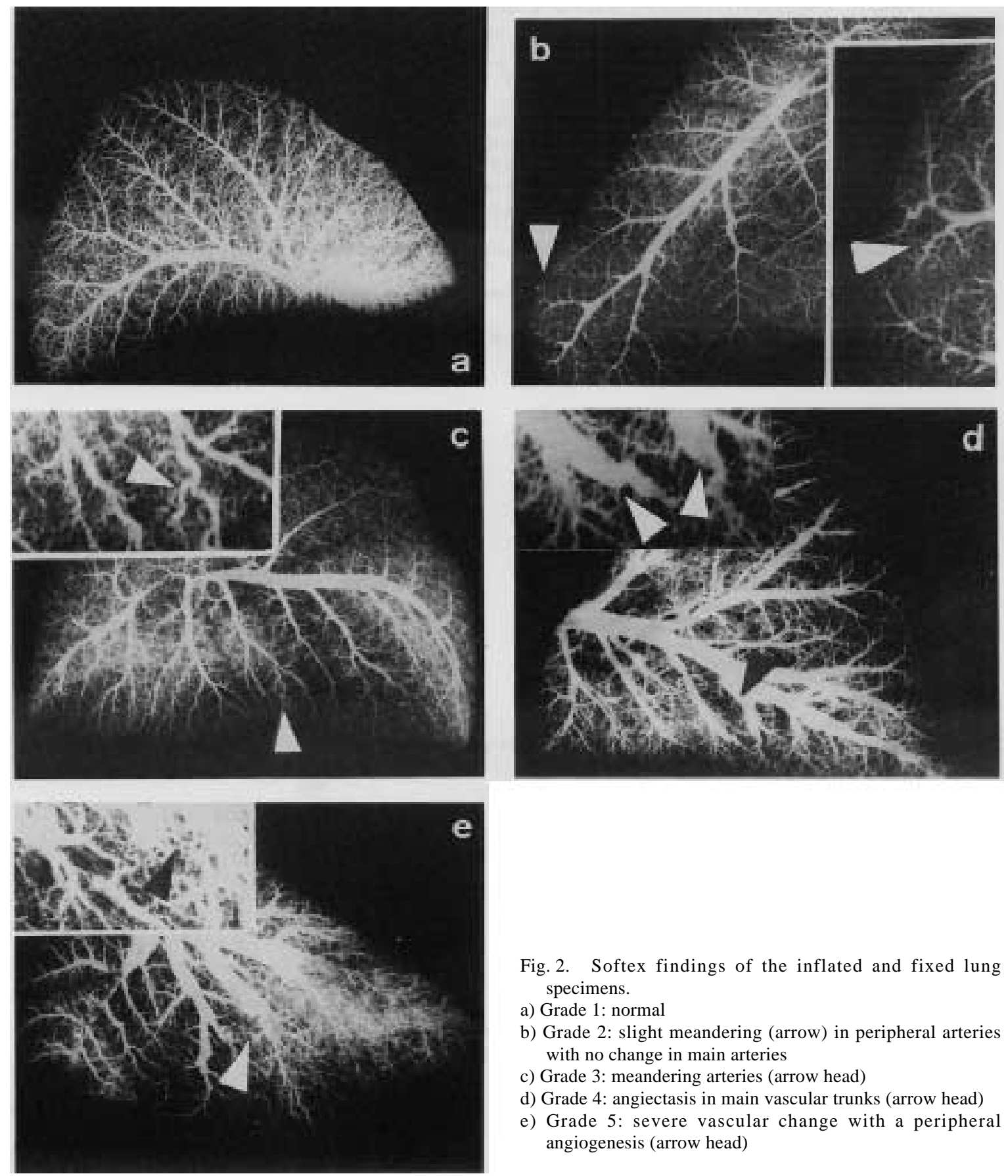

Fig. 2. Softex findings of the inflated and fixed lung specimens.

a) Grade 1: normal

b) Grade 2: slight meandering (arrow) in peripheral arteries with no change in main arteries

c) Grade 3: meandering arteries (arrow head)

d) Grade 4: angiectasis in main vascular trunks (arrow head)

e) Grade 5: severe vascular change with a peripheral angiogenesis (arrow head)

values, and the maximum-frequency-grey level. However, values of the mean and median were not significantly different in two groups.

The values $(\%)$ of maximum frequency $(\mathrm{MaF})$ are shown in Table 2. The MaFs of the normal group were highest in the caudal and lowest in the cranial areas, however in the filariosis group, the highest values were in the cranial and the lowest were the caudal areas. There were no significant difference between the cranial area of the normal lungs and those of the filariosis, however, a significant decrease was observed in the filariosis in the middle and the caudal MaFs. Especially in the caudal, a significant decrease was observed in all parameters of the filariosis in comparison to the normal lungs. The ratio of the first peak frequency to the second peak is shown in Table 3. The ratio of the normal group was approximately $34 \%$, although that of the filariosis group 
Table 1. Comparison of histogram parameter of each chest part between normal and filariosis dogs

\begin{tabular}{|c|c|c|c|c|c|c|}
\hline \multirow[t]{2}{*}{ Paramete } & \multicolumn{3}{|c|}{ Normal $(n=5)$} & \multicolumn{3}{|c|}{ Filariosis $(n=15)$} \\
\hline & Cranial & Middle & Caudal & Cranial & Middle & Caudal \\
\hline Min & $39.1 \pm 7.8^{\mathrm{a}}$ & $30.4 \pm 8.7^{\text {a) }}$ & $26.2 \pm 13.0^{\mathrm{a})}$ & $\left.61.6 \pm 18.9^{\mathrm{b}}\right)$ & $\left.53.8 \pm 17.5^{\mathrm{b}}\right)$ & $49.8 \pm 17.6^{\mathrm{b})}$ \\
\hline $\operatorname{Max}$ & $162.1 \pm 16.2^{\mathrm{a})}$ & $147.1 \pm 13.9^{\mathrm{a})}$ & $141.2 \pm 21.0^{\mathrm{a}}$ & $\left.185.7 \pm 27.5^{\mathrm{b}}\right)$ & $\left.196.5 \pm 27.8^{b}\right)$ & $\left.199.9 \pm 23.7^{\mathrm{b}}\right)$ \\
\hline Mean & $98.9 \pm 15.3^{\mathrm{a})}$ & $77.2 \pm 18.4^{\mathrm{a})}$ & $57.0 \pm 13.5^{\mathrm{a})}$ & $104.2 \pm 24.6^{\mathrm{a})}$ & $80.4 \pm 13.4^{\mathrm{a})}$ & $90.0 \pm 14.3^{\mathrm{b})}$ \\
\hline Med & $96.6 \pm 18.6^{\mathrm{a})}$ & $78.8 \pm 16.2^{\mathrm{a})}$ & $51.9 \pm 18.0^{\mathrm{a})}$ & $105.9 \pm 18.1^{\mathrm{a})}$ & $81.8 \pm 14.9^{\mathrm{a})}$ & $\left.87.3 \pm 15.9^{\mathrm{b}}\right)$ \\
\hline Mode & $95.1 \pm 10.8^{\mathrm{a})}$ & $61.5 \pm 11.7^{\mathrm{a})}$ & $46.5 \pm 11.0^{\mathrm{a})}$ & $99.1 \pm 22.3^{\mathrm{a})}$ & $\left.77.5 \pm 23.9^{\mathrm{b}}\right)$ & $\left.85.9 \pm 25.2^{\mathrm{b}}\right)$ \\
\hline
\end{tabular}

Cranial: cranial part, Middle: middle part, Caudal: caudal part, Min: minimum grey level value, Max: maximum grey level value, Mean: mean grey level value,

Med: median grey level value, Mode: maximum frequency grey level value.

Values are expressed in mean \pm standard deviation.

Values with different superscripts $(a, b)$ show significant difference between each chest part of normal dog and it of filariosis, at $\mathrm{p}<0.05$.

Table 2. Maximum frequency value (\%)

\begin{tabular}{lcc}
\hline Chest part & Normal $(\mathrm{n}=5)$ & Filariosis $(\mathrm{n}=15)$ \\
\hline Cranial & $3.0 \pm 0.5^{\mathrm{a})}$ & $3.4 \pm 1.1^{\mathrm{a})}$ \\
Middle & $\left.3.8 \pm 0.5^{\mathrm{a}}\right)$ & $2.8 \pm 0.8^{\mathrm{b}}$ \\
Caudal & $5.2 \pm 0.6^{\mathrm{a}}$ & $2.0 \pm 0.5^{\mathrm{b}}$ \\
\hline
\end{tabular}

Value are expressed in mean \pm standard deviation.

Values with different superscripts $(\mathrm{a}, \mathrm{b})$ show significant difference between each chest part of normal dog and it of filariosis, at $\mathrm{p}<0.05$.
Table 3. Proportion that the 2nd peak occupies to the 1 st peak

\begin{tabular}{lcc}
\hline Chest part & Normal & Filariosis \\
\hline Cranial & $\left.28.9 \pm 13.6^{\mathrm{a}}\right)$ & $63.8 \pm 21.0^{\mathrm{b}}$ \\
Middle & $37.3 \pm 6.8^{\mathrm{a})}$ & $75.7 \pm 19.2^{\mathrm{b}}$ \\
Caudal & $32.6 \pm 7.4^{\mathrm{a}}$ & $84.5 \pm 13.9^{\mathrm{b}}$ \\
\hline
\end{tabular}

Values $(\%)$ are expressed in mean \pm standard deviation. Values with different superscripts $(a, b)$ show significant difference between each chest part of normal dog and it of filariosis, at $\mathrm{p}<0.05$.

Table 4. Frequency of each histogram pattern in each grade of softex findings

\begin{tabular}{ccccccccc}
\hline \multirow{2}{*}{ Grade } & $\begin{array}{c}\text { Number of } \\
\text { lobe }\end{array}$ & \multicolumn{5}{c}{ Sp } & & \multicolumn{3}{c}{ Mps } \\
\cline { 3 - 8 } \cline { 5 - 8 } & Cranial & Middle & Caudal & Cranial & Middle & Caudal \\
\hline 5 & 26 & 0 & 0 & 3 & 0 & 2 & 21 \\
4 & 23 & 1 & 3 & 3 & 4 & 9 & 3 \\
3 & 18 & 4 & 4 & 0 & 3 & 7 & 0 \\
2 & 20 & 9 & 4 & 0 & 6 & 1 & 0 \\
1 & 3 & 3 & 0 & 0 & 0 & 0 & 0 \\
\hline \multirow{2}{*}{ Total } & 90 & 17 & 11 & 6 & 13 & 19 & 24 \\
\hline
\end{tabular}

Sp: single peak pattern, Mps: multiple peaks pattern.

Softex: soft x-ray examination of the inflated and fixed lung specimens.

was approximately $75 \%$. In the normal group, $60 \%$ of lobes showed under $1.0 \%$ and no lobe showed over $1.5 \%$ in a second peak frequency.

Histogram patterns could be divided into a single peak (Sp) (Fig. 1-1) and multiple peaks (Mps) (Fig. 1-2). The Sp group has a first peak and no second peak of which frequency is over $1.5 \%$. The Mps group has multiple peaks of which frequencies are over $1.5 \%$. In the normal group, all histograms showed $\mathrm{Sp}$. In the filariosis group, 56 lobes showed Mps and 34 lobes showed Sp.

Comparison between soft $\mathrm{x}$-ray findings and histogram patterns in the filariosis lungs are shown in Table 4. On the soft x-ray examination of the filariosis lungs, 87 lobes showed various pathological changes in their circulatory systems, but 3 cranial lobes showed normal findings and showed Sp. There were no significant differences in all parameter values of the lobes compared to the normal lung. Frequencies of Mps increased with the progression of the softex grades. On the other hand, Sp frequencies decreased with the grade levels. MaF of which the histogram pattern was $\mathrm{Sp}$ in the filariosis group are shown in Table 5. MaFs decreased with the softex grades.

Table 6 shows the comparison of the softex grades and MaFs which were under $2 \%$. There were no lobes with under $2 \% \mathrm{MaF}$ in grades 1 to 3. All lobes with under 2\% $\mathrm{MaF}$ were observed in the grade 4 and 5, and the most lobes were right and left caudal lobes. 
Table 5. Relationship between grade of softex findings and peak value of MaF of which histogram is Sp pattern

\begin{tabular}{ccccc}
\hline \multirow{2}{*}{ Grade } & \multicolumn{4}{c}{ Peak value (\%) } \\
\cline { 2 - 5 } & Average & Cranial & Middle & Caudal \\
\hline 5 & $2.0^{\text {cd) }} \pm 0.0$ & - & - & $2.0 \pm 0.0$ \\
4 & $2.8^{\text {bc) }} \pm 0.7$ & $2.1 \pm 0.0$ & $2.6 \pm 7.0$ & $3.3 \pm 0.5$ \\
3 & $3.2^{\text {b) }} \pm 0.9$ & $3.1 \pm 0.6$ & $3.2 \pm 1.1$ & - \\
2 & $3.4^{\text {ab) }} \pm 0.6$ & $3.3 \pm 0.6$ & $3.7 \pm 0.6$ & - \\
1 & $5.1^{\text {a) }} \pm 1.1$ & $5.1 \pm 1.1$ & - & - \\
\hline
\end{tabular}

Peak value means mean maximum frequency in MaF.

Values are expressed in mean \pm standard deviation.

-: There was no case which showed Sp pattern.

Values with different superscripts (a,b,c,d) show significant difference at $\mathrm{p}<0.05$.

Table 6. Relationship between grade of softex findings and frequency (\%) of which $\mathrm{MaF}$ is below $2 \%$ in each lung lobe with filariosis

\begin{tabular}{ccrrccc}
\hline Grade & $\mathrm{Ra}$ & $\mathrm{Rc}$ & $\mathrm{Rd}$ & $\mathrm{La}$ & $\mathrm{Lc}$ & $\mathrm{Ld}$ \\
\hline 5 & 0.0 & 0.0 & 46.2 & 0.0 & 3.8 & 42.3 \\
4 & 0.0 & 17.4 & 0.0 & 0.0 & 4.3 & 4.3 \\
3 & 0.0 & 0.0 & 0.0 & 0.0 & 0.0 & 0.0 \\
2 & 0.0 & 0.0 & 0.0 & 0.0 & 0.0 & 0.0 \\
1 & 0.0 & 0.0 & 0.0 & 0.0 & 0.0 & 0.0
\end{tabular}

R: right side, L: left side, a: cranial part, c: middle part, d: caudal part.

\section{DISCUSSION}

The present results clearly demonstrate that a histogram of a normal dog, aided by the computer processing of a survey thoracic $\mathrm{x}$-ray, showed the characteristic Sp pattern, changed its pattern to Mps with lesions in the pulmonary vascular system.

In comparison with parameters of the normal dog, values of Min and Max in the filariosis lungs significantly increased. The increase of Min value means decrease in black components, and the increase of Max value indicates an increase in white components in a lung field. From the softex findings, the pulmonary arterial lesions were clearly demonstrated in the filariosis lungs, and their main pathological changes were angiectasis by embolism. These vascular dysfunctions will bring lung parenchymal pathological changes such as pulmonary edema and atelectasis. It is known that an attenuation of $\mathrm{x}$-ray permeability occurs in the presence of various lesions such as thrombosis and angiectasis $[1,3,4,6,8,9,14]$. Various abnormal densities will be accompanied by pulmonary lesions, and will compose multiple peaks. These changes will cause the decrease of $\mathrm{MaF}$ in the filariosis lungs. Med and Mean did not change sensitively with the degree of lung lesion, but their values significantly increased in the caudal area which showed the most severe pathological vascular lesions, so any changes of these parameters will indicate severe lung dysfunction. Therefore, it is conceivable that the histogram also reflects the lesions which vascular lesions are related to. In the normal lungs, histogram patterns showed $\mathrm{Sp}$, indicating that normal lung tissue expresses very simple density distribution. However, in the filariosis lungs, 34 lobes showed $\mathrm{Sp}$ in spite of vascular lesions revealed by the soft x-ray examination. From the results of tests for MaF, these cases showed significant decrease of MaF, especially in softex grades 4 and 5. This decrease in MaF indicates the disappearance of a particular density which is observed in the normal lung. Based on the present results, the examination of a histogram by digital processing of survey $\mathrm{x}$-ray film produce a histogram pattern and $\mathrm{MaF}$ which will be highly important factors in the diagnosis of lung diseases. In the examination of each lobe, these abnormal findings appeared mostly in the caudal lobe, and soft $x$-ray examination revealed that vascular lesions were also most severe in this lobe. These results are well in agreement with previous papers concerning with pathological survey of filariosis [3, 4, 14].

In the present study, the inflated and fixed lung specimen was employed in order to clarify the pulmonary arterial system. It is reported that softex findings are related to pathologic findings in the all types of pulmonary lesions [2], and even density histogram is so. So this technique is most suitable for observing lung structure and the lung's blood vessels, and it is excellent that is able to observe the lung whole in comparison with the pathological histology. Actually, we observed clearly lung arterial lesion in the this study. This technique would be suitable for the observations of various canine lung arterial lesions.

\section{REFERENCES}

1. Adcock, J. L. 1961. Pulmonary arterial lesions in canine dirofilariosis. Am. J. Vet. Res. 22: 655-662.

2. Bedros, M. and Edwin, T. D. 1984. Preparation of inflated lung specimens. pp. 4-12. In: The Lung Radiographic-Pathologic Correlations, 2nd ed. (Heizman, E. R. ed.), The C. V. Mosby, ST. Louis.

3. Calvert, C. A. 1987. The best tests for evaluating the heart worm-infected dog. Am. J. Vet. Med. 82: 238-253.

4. Carlisle, C. H. 1980. Canine dirofilariosis: It's radiographic appearance. Am. J. Vet. Rad. 21: 123-130.

5. Cristopher, R. L. 1994. The Canine Lung. pp. 304-346. In: Textbook of Veterinary Diagnostic Radiology, 2nd ed. (Thrall, D. E. ed.), W. B. Saunders, Philadelphia.

6. Fluckiger, M. A. and Gomez, J. A. 1984. Radiographic findings in dogs with spontaneous pulmonary thrombosis or embolism. Am. J. Vet. Rad. Assoc. 25: 124-131.

7. Kitagawa, H., Yasuda, K., and Kitoh, K. and Sasaki, Y. 1995. Blood gas analysis in dogs with pulmonary heart worm disease. J. Vet. Med. Sci. 57: 33-37.

8. Henniger, G. R. and Ferguson, R. W. 1987. Pulmonary vascular sclerosis as we result of Dirofilaria immitis infection in a dog. Am. J. Vet. Med. Assoc. 131: 336-341.

9. Jackson, W. F. 1969. Radiographic examination of the heart worm infected patient. Am. J. Vet. Med. Assoc. 154: 380386.

10. Miyatake, K., Minami, S. and Okamoto, Y. 1997. Computerized digital image processing on a survey radiograph of canine 
lung. J. Jpn. Vet. Med. Assoc. 50: 99-102 (in Japanese).

11. Rawlings, C. A. 1981. The lungs. pp. 377-393. In: Pathophysiology in Small Animal Surgery (Bojarb, M. J. ed.), Lea and Febiger, Philadelphia.

12. Robinson, N. E. and O'handley, P. 1981. Thoracic physiology. pp. 324-332. In: Pathophysiology in Small Animal Surgery (Bojarb, M. J. ed.), Lea and Febiger, Philadelphia.

13. Uehara, Y., Koga, M. and Takahashi, M. 1995. Determina- tion of cardiac output by echocardiography. J. Vet. Med. Sci. 57: 33-37.

14. Whiteley, H. E. 1988. Your diagnostic protocol for Dirofilaria immitis infection in dogs. Am. J. Vet. Med. 83: 328-338.

15. Yarns, D.A. and Tashjian, R.J. 1967. Cardio pulmonary values in normal and heart worm infected dogs. Am. J. Vet. Res. 28: $1461-1473$. 